\section{OS GASTOS TRIBUTÁRIOS COM ESPORTE NOS GOVERNOS LULA E DILMA}

\author{
TAX REVENUE SPENDING ON SPORTS DURING THE LULA AND ROUSSEFF \\ ADMINISTRATIONS
}
LOS GASTOS TRIBUTARIOS CON DEPORTE EN LOS GOBIERNOS LULA Y DILMA

\author{
Fernando Henrique Silva Carneiro*, Wagner Barbosa Matias**, \\ Marcelo Resende Teixeira**, Fernando Mascarenhas***
}

\begin{abstract}
Palavras chave: Fundo público. Financiamento governamental. Esporte.

Gasto tributário.

Resumo: Este estudo teve por objetivo analisar a configuração do financiamento público do esporte via gastos tributários nos governos Lula e Dilma. A pesquisa tem caráter quantitativo-qualitativo e se apoiou em levantamento documental. Foram analisados três indicadores: fontes de financiamento, magnitude do gasto e direcionamento do gasto. Há cinco diferentes tipos de legislações que deram base ao financiamento de gastos tributários, a maioria foi criada nos governos Lula e Dilma, sendo a maioria dos tributos desonerados aqueles vinculados aos impostos sobre a renda e contribuições sociais, que financiam a seguridade social. Os gastos tributários com esporte contribuíram significativamente para aumentar o financiamento do esporte, sobretudo, a partir da Lei de Incentivo ao Esporte e dos megaeventos esportivos. 0 direcionamento dos gastos tributários ocorreu prioritariamente para a categoria "Esporte, Educação, Lazer e Inclusão Social", havendo gastos também com Esporte de Alto Rendimento e megaeventos.
\end{abstract}

Keywords:

Public fund. Government funding. Sport. Tax spending.

Palabras clave: Fondo público. Financiación gubernamental. Deporte. Gasto tributario.
Abstract: This study analyzes the status of public funding of sports by tax revenues during Brazil's Lula and Rousseff administrations. The study was quantitative and qualitative and based on documentary survey. Three indicators were examined: spending sources, scale and focus. Five different types of legislation provided the basis for spending tax revenues, most of which were created by those administrations. Most tax exemptions were linked to income taxes and social contributions that fund social security. Tax revenue spending on sports contributed significantly to increase sports funding, especially as a result of the Sports Incentive Law and the mega sporting events. The priority focus for spending tax revenues was the category "Sports, Education, Leisure and Social Inclusion" as well as High Performance Sports and mega events.

Resumen: Este estudio tuvo por objetivo analizar la configuración de la financiación pública del deporte a través de gastos tributarios en los Gobiernos Lula y Dilma. La investigación tiene carácter cuantitativo-cualitativo y se apoyó en levantamiento documental. Se analizaron tres indicadores: fuentes de financiación, magnitud del gasto y destino del gasto. Hay cinco diferentes tipos de legislaciones que dieron base a la financiación de gastos tributarios, la mayoría fue creada en los Gobiernos Lula y Dilma y la mayoría de los tributos que tuvieron exención fueron aquellos vinculados a impuestos sobre la renta y contribuciones sociales que financian la seguridad social. Los gastos tributarios con deporte contribuyeron significativamente para aumentar la financiación del deporte, sobre todo desde la Ley de Incentivo al Deporte y de los megaeventos deportivos. El destino de los gastos tributarios se encaminó prioritariamente hacia la categoría "Deporte, Educación, Ocio e Inclusión Social", aunque se gastó también con Deporte de Alto Rendimiento y megaeventos.
*Instituto Federal de Goiás. Goiânia GO, Brasil.

E-mail: fernandohenriquesc@gmail.com

${ }^{* *}$ Ministério do Esporte e Secretaria de Estado de Educação do Distrito Federal. Brasília, DF, Brasil.

E-mail: wagner.matias@outlook.com; marinresende@yahoo.com.br

***Universidade de Brasília. Brasília, DF, Brasil.

E-mail: fernandom@unb.br

Recebido em: 13-12-2018

Aprovado em: 04-04-2019

Publicado em: 31-10-2019

DOI:

hitps://doi.org/10.22456/1982-8918.88903

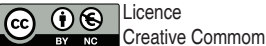




\section{INTRODUÇÃOO}

O financiamento público federal do esporte brasileiro é formado por diferentes fontes de recursos, que podem ser classificadas em: orçamentárias, extraorçamentárias e gastos tributários (MASCARENHAS, 2016; CARNEIRO; MASCARENHAS, 2018). As fontes orçamentárias são os recursos do orçamento público da União; as extraorçamentárias são formadas, principalmente, por recursos de loterias e patrocínio das estatais; e os gastos tributários são desonerações e isenções tributárias relacionadas ao setor esportivo - tributos que deixaram de compor o orçamento federal.

A maior parte dos estudos sobre o financiamento do esporte brasileiro se pauta no orçamento público federal (ATHAYDE; SALVADOR; MASCARENHAS, 2015; MASCARENHAS, 2016; CASTRO, 2016; TEIXEIRA et al., 2018; CARNEIRO et al., 2019), haja vista ser a fonte mais visível do fundo público (SALVADOR, 2012). As fontes extraorçamentárias contam com estudos sobre loterias (ALMEIDA; MARCHI JÚNIOR 2011; 2012), sobre patrocínio das estatais (PEREIRA, 2017) e sobre ambos (TEXEIRA; MATIAS; MASCARENHAS, 2017). No caso específico dos gastos tributários, objeto deste estudo, identificam-se apenas os trabalhos de Bastidas e Bastos (2011) e de Matias et al. (2015), ainda assim, apenas sobre um elemento dos gastos tributários com esporte, a Lei de Incentivo ao Esporte - LIE (BRASIL, 2006).

Os gastos tributários são desonerações tributárias e isenções fiscais que estão relacionadas a um conjunto de medidas legais de financiamento público não orçamentário das políticas públicas (SALVADOR, 2015). Ressalta-se que se está pautando no conceito de gasto tributário a partir da Receita Federal do Brasil - RFB (BRASIL, 2018a, p. 9), isto é, gastos indiretos do governo concretizados por meio do sistema tributário "[...] visando a atender objetivos econômicos e sociais e constituem-se em uma exceção ao sistema tributário de referência, reduzindo a arrecadação potencial e, consequentemente, aumentando a disponibilidade econômica do contribuinte". Dessarte, embora o sistema tributário tenha a função de arrecadar recursos para o Estado, esse é permeado por gastos tributários.

Pellegrini (2014, p. 1), ao analisar a experiência internacional e do Brasil, aponta que: "há uma percepção geral de que os gastos tributários podem ser úteis para alcançar certos objetivos de interesse público, mas, também, de que precisam ser utilizados com parcimônia". Isto ocorre porque alguns riscos podem ser ocasionados com o aumento dos gastos tributários: elevação da regressividade do sistema tributário; aumento da ineficiência na alocação dos recursos públicos; elevação da complexidade da estrutura tributária; e falta de devido controle, podendo ameaçar o equilibrio das contas públicas (PELLEGRINI, 2014).

Os gastos tributários se colocam em determinadas situações como alternativa às ações políticas de governo, ou seja, buscam promover o desenvolvimento econômico e/ou social, não realizado no orçamento, mas por meio do sistema tributário (SALVl; PAULA; LOURES, 2003). Neste sentido, Beghin, Chaves e Ribeiro (2010) colocam que o Estado faz política pública ao estabelecer desonerações tributárias, haja vista utilizar isso como ferramenta para reduzir o ônus sobre determinados agentes econômicos, buscando atingir objetivos sociais e/ou econômicos. Os gastos tributários podem ter um caráter compensatório, na medida em que o governo deixa de atender adequadamente à população com os serviços que são de sua 
responsabilidade, mas também podem ter um caráter incentivador, quando o governo tem a intenção de desenvolver determinado setor ou região (BRASIL, 2018a).

Ao longo dos governos Lula da Silva (2003-2010) e Dilma Rousseff (2011-2016)', houve crescimento dos gastos tributários, que passaram de cerca de $R \$ 48,74$ bilhões em 2004 para R\$265,13 bilhões em 2016 (TRANSPARÊNCIA NO ESPORTE, 2019) - valores deflacionados -, ou seja, o gasto aumentou mais de 5,4 vezes em comparação ao início para o final da coalizão liderada pelo Partido dos Trabalhadores (PT). Desta forma, esta foi uma das maneiras utilizadas por esses governos para 0 atendimento de determinados objetivos econômicos e sociais.

Salvador (2015) apresenta que a concessão de generosos gastos tributários foi uma das alternativas encontradas pelos governos Lula e Dilma, como elemento anticíclico para lidar com a crise econômica, sobretudo, a partir de 2009, buscando socorrer as empresas em momentos de crise do capitalismo. Houve redução do Imposto sobre Produtos Industrializados (IPI) para o setor automotivo no final de 2008, já em 2009, tal redução alcançou outros setores econômicos, como: bens de consumo duráveis, material de construção, bens de capital, motocicletas, móveis e alguns itens alimentícios (SALVADOR, 2015). Mais medidas foram tomadas pelo governo Lula para socorrer o capital privado em 2010, a prorrogação da redução do IPI para indústria automobilística e para eletrodomésticos da linha branca (geladeiras, fogões, máquinas de lavar) (SALVADOR, 2015).

Essas medidas tiveram continuidade no governo Dilma, tendo sido lançado em 20110 "Plano Brasil Maior" - colocado como uma política industrial para sustentar o desenvolvimento. Para Salvador (2015), a chave mestra do referido plano foram as desonerações tributárias, tendo essas se ampliado com o aprofundamento da crise internacional. Tanto que, em 2014, as desonerações atingiram 42 setores, tendo sido um dos instrumentos anticíclicos do governo Dilma (PINTO et al., 2016).

Destaca-se que nesse período foram implementadas diversas políticas de isenção e desoneração fiscal no setor esportivo, exemplo disso são a LIE e as desonerações para os megaeventos esportivos. Sendo assim, busca-se com este estudo analisar a configuração do financiamento público do esporte via gastos tributários nos governos Lula e Dilma.

\section{DELINEAMENTO METODOLÓGICO}

Este estudo tem caráter quantitativo-qualitativo e se apoiou em levantamento documental. $O$ período de análise é de 2006 a 2015, pois embora os governos Lula e Dilma tenham ido de $1^{0}$ janeiro de 2003 a 31 de agosto de 2016, nos relatórios da RFB os gastos tributários de bases efetivas vão apenas de 2006 a 2015.

A coleta de dados foi realizada no Portal da Legislação do Governo Federal para identificar as legislações sobre gastos tributários. No referido portal foram utilizados os termos "esporte" e "desporto" para identificar as diferentes legislações sobre esporte, a partir disso foram selecionadas aquelas que trataram, especificamente, de gastos tributários no período dos governos Lula e Dilma.

10 segundo mandato de Dilma deveria ter ido até dezembro de 2018, contudo seu governo teve fim em 31 de agosto de 2016 devido ao processo de impeachment. 
Também foi realizada coleta de dados em diferentes relatórios da RFB (BRASIL, 2018b) para identificar os gastos tributários no período supracitado. Embora haja consenso na literatura internacional sobre os objetivos dos gastos tributários (SALVADOR, 2015), o mesmo não pode ser dito em relação à metodologia adotada pelos diferentes países para apuração

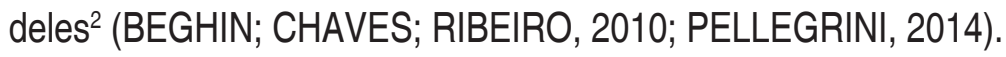

De 2006 a 2011 foram utilizados os "Demonstrativos de Gastos Tributários - Estimativas Bases Efetivas" e de 2012 a 2015 se valeu dos "Demonstrativos dos Gastos Tributários - Bases Efetivas", ambos podem ser acessados em RFB (BRASIL, 2018b). Nos referidos relatórios, os gastos tributários são apresentados a partir da classificação funcional das despesas, do mesmo modo que no orçamento federal, havendo a função "Desporto e lazer", tendo sido apenas os gastos tributários nesta função que foram utilizados na pesquisa.

A análise dos dados será realizada a partir da proposta metodológica desenvolvida por Carneiro e Mascarenhas (2018), em que apresentam que devem ser analisados três indicadores sobre o financiamento e gasto com esporte, neste caso esses foram adaptados para analisar a fonte de gastos tributários: a) fontes de financiamento - visa compreender a origem dos recursos, sendo necessário analisar as legislações vigentes, bem como os diferentes tributos no caso dos gastos tributários que deixaram de ser arrecadados; b) magnitude do gasto - se relaciona ao montante gasto em cada ano, tendo uma análise longitudinal, demonstrando a evolução do gasto, também apontam que se deve comparar em proporção a outros elementos, como o total de gasto tributário em cada ano; e c) direção do gasto - está articulado ao direcionamento dos recursos, estabelecendo aquilo que foi priorizado.

Os dados financeiros utilizados foram deflacionados pelo Índice Geral de Preços Disponibilidade Interna ${ }^{3}$ (IGP-DI), média anual, calculado pela Fundação Getulio Vargas, a preços de 2015, haja vista a necessidade de atualizar os valores para comparações longitudinais, eliminando os efeitos da inflação e da desvalorização da moeda.

A seguir se apresentam e discutem os dados do estudo a partir de três subseções, as fontes de financiamento, a magnitude do gasto e o direcionamento dos gastos tributários com esporte.

\section{FONTES DE FINANCIAMENTO DE GASTOS TRIBUTÁRIOS}

No Quadro 1 são apresentados os diferentes tipos de desonerações/isenções tributárias que compuseram a fonte de gastos tributários do esporte ao longo dos governos Lula e Dilma. Isso foi realizado a partir da análise das legislações de gastos tributários para o esporte, tendo possibilitado identificar os tributos desonerados e o período de vigência.

2 Estudos como o de Pellegrini (2014) e Villela, Lemgruber e Jorratt (2009) fizeram uma análise da literatura internacional sobre os conceitos e formas de apuração dos gastos tributários. 
Quadro 1 - Legislação dos gastos tributários para o esporte a partir do tipo de desoneração/isenção tributária.

\begin{tabular}{|c|c|c|c|}
\hline Tipo & Legislação & Tributos desonerados & Vigência \\
\hline $\begin{array}{l}\text { Desoneração das } \\
\text { entidades recreativas } \\
\text { sem fins lucrativos }\end{array}$ & $\begin{array}{l}\text { Constituição } \\
\text { Federal } \\
\text { 1988; Lei no } \\
\text { 9.532/1997; } \\
\text { e Medida } \\
\text { Provisória } \\
\text { 2.158-35/2001 }\end{array}$ & $\begin{array}{l}\text { Isenção de Imposto de Renda de Pessoa } \\
\text { Jurídica (IRPJ), Contribuição Social sobre } \\
\text { Lucro Líquido (CSLL) e Contribuição para } \\
\text { o Financiamento da Seguridade Social } \\
\text { (COFINS) }\end{array}$ & Indeterminado \\
\hline $\begin{array}{l}\text { Isenção de impostos } \\
\text { na fabricação nacional } \\
\text { e na importação de } \\
\text { equipamentos e materiais } \\
\text { esportivos }\end{array}$ & $\begin{array}{c}\text { Leis no: } \\
\text { 10.451/2002; } \\
\text { 11.116/2005; } \\
11.827 / 2008 ; \mathrm{e} \\
12.649 / 2012 \\
\end{array}$ & Isenção de Imposto de Importação (II) e IPI & $31 / 12 / 2015$ \\
\hline $\begin{array}{c}\text { Isenção fiscal de } \\
\text { patrocínios e doações } \\
\text { de pessoas físicas e } \\
\text { jurídicas no apoio direto } \\
\text { ao esporte }\end{array}$ & $\begin{array}{c}\text { Leis no: } \\
\text { 11.438/2006; } \\
\text { 11.472/2007; e } \\
\text { 13.155/2015 }\end{array}$ & $\begin{array}{l}\text { Limite máximo de desoneração 6\% Imposto } \\
\text { de Renda de Pessoa Física (IRPF) e 1\% IRPJ }\end{array}$ & $\begin{array}{l}\text { Inicialmente } \\
\text { até } 2015 \text {, foi } \\
\text { prorrogada até } \\
2022 .\end{array}$ \\
\hline $\begin{array}{l}\text { Isenção de tributos } \\
\text { nas importações de } \\
\text { bens recebidos como } \\
\text { premiação em evento } \\
\text { esportivo realizado no } \\
\text { exterior e de bens e } \\
\text { materiais consumidos, } \\
\text { distribuídos ou utilizados } \\
\text { em evento esportivo no } \\
\text { Brasil }\end{array}$ & $\begin{array}{l}\text { Lei } n^{\circ} \\
\text { 11.488/2007; } \\
\text { e Decretos no } \\
6.759 / 2009 ; \text { e } \\
7.213 / 2010\end{array}$ & $\begin{array}{l}\text { Isenção de II, IPI, Contribuição para o } \\
\text { Programa de Integração Social (PIS) e o } \\
\text { Programa de Formação do Patrimônio do } \\
\text { Servidor Público (PASEP), COFINS e de } \\
\text { Contribuições de Intervenção no Domínio } \\
\text { Econômico (CIDE)-Combustíveis }\end{array}$ & Indeterminado \\
\hline $\begin{array}{c}\text { Desonerações tributárias } \\
\text { voltadas à realização dos } \\
\text { megaeventos esportivos }\end{array}$ & $\begin{array}{l}\text { Leis no: } \\
\text { 12.780/2013; } \\
\text { 13.265/2016; } \\
\text { 12.350/2010; e } \\
\text { 12.663/2012 }\end{array}$ & $\begin{array}{l}\text { Isenção de IPI, II, PIS/PASEP, COFINS, } \\
\text { AFRMM, Adicional ao Frete para a } \\
\text { Renovação da Marinha Mercante (AFRMM), } \\
\text { Imposto de Renda Retido na Fonte (IRRF), } \\
\text { Imposto sobre Operações Financeiras (IOF), } \\
\text { CSLL, CIDE-Combustíveis, Contribuição } \\
\text { para o Desenvolvimento da Indústria } \\
\text { Cinematográfica Nacional (CONDECINE), } \\
\text { contribuições administradas pela SRFB e } \\
\text { Contribuição para o Programa de Estímulo } \\
\text { à Interação Universidade-Empresa para o } \\
\text { Apoio à Inovação. }\end{array}$ & $\begin{array}{l}\text { RECOPA - } \\
\text { 30/06/2014 } \\
\text { Copa das } \\
\text { Confederações } \\
2013 \text { e Copa } \\
\text { 2014 - } \\
\text { 31/12/2015 } \\
\text { Jogos } \\
\text { Olímpicos e } \\
\text { Paralímpicos } \\
\text { Rio 2016 - } \\
\text { 31/12/2017 }\end{array}$ \\
\hline
\end{tabular}

Fonte: BRASIL. Portal da Legislação do Governo Federal. (Elaboração própria)

Portanto, fica claro que ao longo do tempo houve o estabelecimento de legislações que foram garantindo recursos de gastos tributários para o esporte, sendo que a única que foi estabelecida antes dos governos Lula e Dilma foi a de desoneração das entidades recreativas sem fins lucrativos. Outros setores, como a assistência social, a saúde, a ciência, a cultura e a educação, também contam com desoneração das entidades sem fins lucrativos (BRASIL, 2018b).

De acordo com Boudens (2007), os constituintes de 1988 quiseram que fossem criadas leis específicas para os incentivos fiscais, dentre esses o esporte, buscando evitar as "farras 
das isenções fiscais". Enquanto o governo de Fernando Henrique Cardoso (1995-2002) via as desonerações/isenções para o esporte com ressalvas, entendendo que o setor deveria estabelecer parcerias com a iniciativa privada (BOUDENS, 2007), o governo Lula entendia que esse processo deveria ser capitaneado pelo governo federal (CARNEIRO, 2018), elemento que se consubstanciou pela criação das legislações presentes no Quadro 1.

O Tribunal de Contas da União (TCU) na TC022.993/2009-9 faz uma avaliação sobre a LIE que tem validade para outras isenções/desonerações fiscais, e essa é:

[...] uma forma simplificada de utilização de recursos públicos, pois a tais valores não se aplicam os trâmites e controles orçamentários estabelecidos, sendo executados diretamente por organizações não governamentais ou entes governamentais fora da esfera federal. Além disso, tais recursos não se submetem a eventuais contingenciamentos de despesa pelo Poder Executivo (BRASIL. TCU, 2009, p. 2).

Embora já houvesse legislações de gastos tributários para realização de eventos esportivos no Brasil, foram criadas, a partir de 2010, legislações voltadas aos megaeventos esportivos, especificamente, a Copa das Confederações FIFA 2013, a Copa FIFA 2014 e os Jogos Rio 2016.

Para além de apontar as legislações com os tributos que compuseram os gastos tributários, apresentam-se na Tabela 1, os diferentes impostos, contribuições sociais e contribuições de intervenção no domínio econômico, que fizeram parte dos gastos tributários com esporte de 2006 a 2015.

Tabela 1 - Distribuição dos gastos tributários para o esporte por tipo de tributo - Série 2006-2015 (valores deflacionados pelo IGP-DI a preços de 2015 em milhões $\mathrm{R} \$$ e \%)

\begin{tabular}{lcc}
\hline Tipo de tributação & Total (R\$) & $\%$ \\
\hline Impostos & $2.727,53$ & 53,18 \\
Imposto de Renda de Pessoa Jurídica (IRPJ) & $2.570,04$ & 50,11 \\
Imposto sobre Produtos Industrializados (IPI) & 54,81 & 1,07 \\
Impostos de Importação (II) & 40,87 & 0,80 \\
Imposto de Renda de Pessoa Física (IRPF) & 34,89 & 0,68 \\
Imposto sobre a Renda Retido na Fonte (IRRF) & 20,26 & 0,39 \\
Imposto sobre Operações Financeiras (IOF) & 6,67 & 0,13 \\
Contribuições sociais & $2.399,38$ & 46,78 \\
Contribuição para o Financiamento da Seguridade Social (COFINS) & $1.709,56$ & 33,33 \\
Contribuição Social sobre Lucro Líquido (CSLL) & 455,33 & 8,88 \\
Contribuição para previdência social & 125,98 & 2,46 \\
Contribuição Social para o PIS/PASEP & 108,51 & 2,12 \\
Contribuições de Intervenção no Domínio Econômico (CIDE) & 2,22 & 0,04 \\
Adicional ao Frete para a Renovação da Marinha Mercante (AFRMM) & 2,22 & 0,04 \\
\hline Total & $5.129,12$ & 100,00 \\
\hline
\end{tabular}

Fonte: Demonstrativos de gastos tributários (BRASIL, 2018b). (Elaboração própria)

Como pode ser visto na Tabela 1, a maior parte do gasto tributário com esporte foi proveniente de impostos, tendo representado no período $53,18 \%$ (2,72 bilhões). A maioria dos impostos desonerados está ligada à renda, haja vista que $96,25 \%$ dos impostos foram formados por IRPJ, IRPF e IRRF. O destaque é o IRPJ, pois somente esse abarcou $50,11 \%$ de 
todo gasto tributário. Salvador (2015) aponta que as desonerações a partir da renda e do IPI se colocam como os principais desfinanciadores do orçamento federal, no âmbito mais geral.

As contribuições sociais representaram 46,78\% (2,39 bilhões) dos recursos de gastos tributários no período, tendo sido a principal composição a COFINS (R\$ 1,70 bilhão), seguida pela CSLL ( $R \$ 455,33$ milhões). Assim, recursos que seriam direcionados para seguridade social acabaram não sendo recebidos pelo Estado e passaram a ser gastos tributários do esporte. De acordo com Salvador (2015), a seguridade social enfrenta dificuldades de financiamento deste seu surgimento na Constituição Federal de 1988, tendo aprofundado suas dificuldades pelos gastos tributários - como os para o esporte -, pois a seguridade é financiada por contribuições sociais como, a COFINS, o PIS, a CSLL e a contribuição para a previdência social.

Desta maneira, fica claro que o financiamento do esporte via gastos tributários está concentrado nas desonerações de PJ e na COFINS. A presença de gastos tributários com esporte cumpre um papel social e econômico (CARNEIRO, 2018), pois ao estabelecer estes recursos para o setor possibilitou aumentar seu financiamento. Discutindo as diferentes fontes de recursos de gastos tributários, passa-se a analisar a magnitude desse.

\section{MAGNITUDE DO GASTO TRIBUTÁRIO}

Analisar a magnitude do gasto tributário com esporte é importante por mostrar a quantidade de recursos públicos desta fonte que deixaram de compor o orçamento federal. De 2006 a 2015, o montante de gasto tributário com o esporte foi de $\mathrm{R} \$ 5,12$ bilhões. 0 estudo de Carneiro (2018), que analisou todo o financiamento público federal do esporte de 2004 a 2015 , apontou que $21,17 \%$ dos recursos para o esporte no período foram de gastos tributários, portanto, esses tiveram uma parcela importante de contribuição para o financiamento esportivo nos governos Lula e Dilma.

Ao longo dos dez anos analisados, o gasto tributário com esporte representou 0,25\% do total de gasto tributário do governo federal. Na Tabela 2 se apresenta a evolução do gasto tributário com esporte em relação ao total de gasto tributário em cada ano.

Tabela 2 - Participação do gasto tributário com esporte em relação a todo gasto tributário - Série 2006-2015 (valores deflacionados pelo IGP-DI a preços de 2015 em milhões R\$ e \%)

\begin{tabular}{cccc}
\hline Ano & $\begin{array}{c}\text { Gastos tributários com } \\
\text { esporte }\end{array}$ & $\begin{array}{c}\text { Total de gastos } \\
\text { tributários }\end{array}$ & $\begin{array}{c}\text { \% gastos tributários do esportel } \\
\text { total de gastos tributários }\end{array}$ \\
\hline 2006 & 289,05 & $114.832,66$ & $0,25 \%$ \\
2007 & 380,94 & $152.985,96$ & $0,25 \%$ \\
2008 & 407,70 & $162.947,81$ & $0,25 \%$ \\
2009 & 416,83 & $171.452,93$ & $0,24 \%$ \\
2010 & 513,22 & $197.107,86$ & $0,26 \%$ \\
2011 & 547,87 & $209.478,11$ & $0,26 \%$ \\
2012 & 556,21 & $230.976,82$ & $0,24 \%$ \\
2013 & 773,01 & $266.816,79$ & $0,29 \%$ \\
2014 & 716,57 & $289.716,13$ & $0,25 \%$ \\
2015 & 531,36 & $288.690,84$ & $0,18 \%$ \\
\hline Total & 5132,77 & $2.085 .005,90$ & $0,25 \%$ \\
\hline
\end{tabular}


Como pode ser visto, em oito dos dez anos analisados, os valores ficaram entre $0,24 \%$ e $0,26 \%$ dos gastos tributários com esporte em relação ao gasto tributário total, portanto, 0 esporte não foi um dos setores prioritários de gastos tributários, embora os recursos desta fonte tenham sido importantes para aumentar o financiamento esportivo. Salvador (2015), ao analisar os gastos tributários com as diferentes funções de 2010 a 2014, demonstrou que a prioridade envolve funções como "Comércio e serviço", "Indústria", "Trabalho", "Saúde", "Agricultura" e "Assistência social", estando a função "Desporto e lazer" dentre aquelas que menos tiveram recursos.

Figura 1- Evolução do gasto tributário do esporte por tipo de isenção/desoneração tributária - Série 2006-2015 (valores deflacionados pelo IGP-DI a preços de 2015 em R \$ milhões)

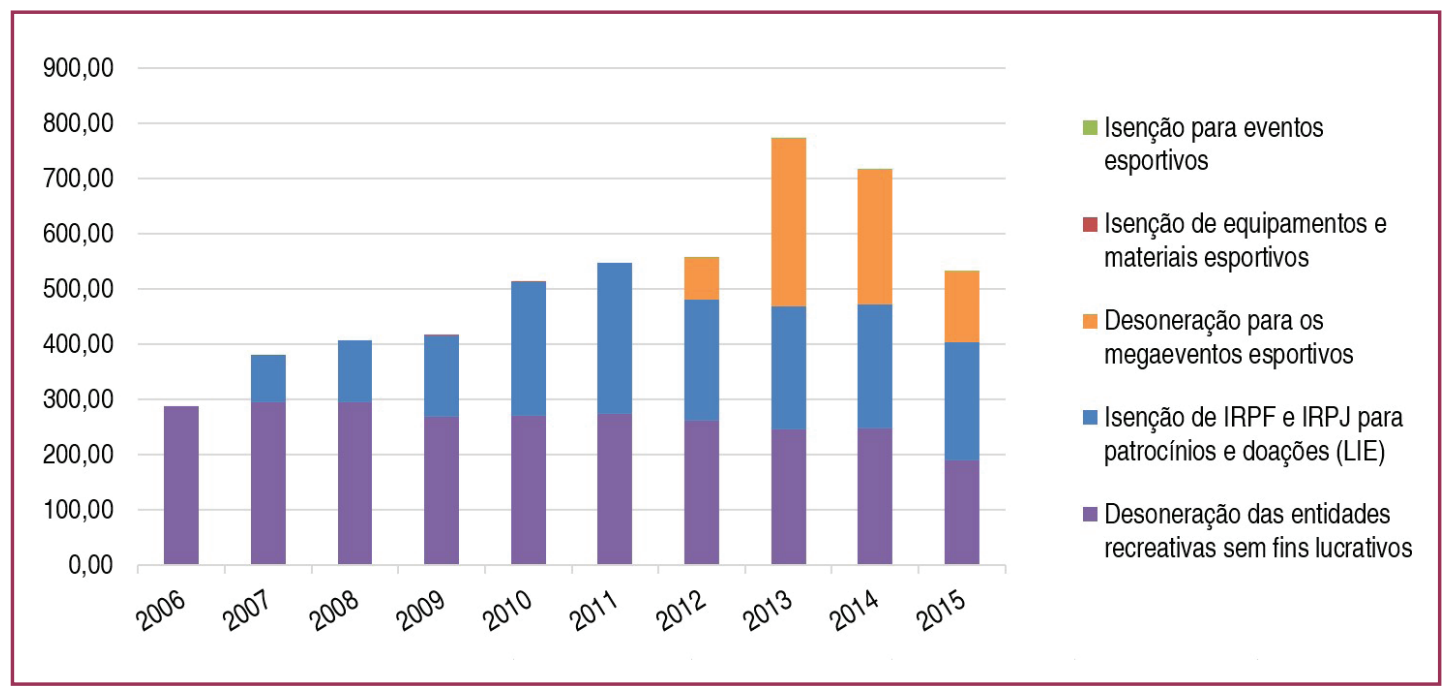

Fonte: Demonstrativos de gastos tributários (BRASIL, 2018b). (Elaboração própria)

Na Figura 1 se apresenta a evolução do gasto tributário por tipo de isenção/desoneração. Fica claro que houve crescimento do gasto tributário ao longo do tempo no esporte, tanto que esse foi de $\mathrm{R} \$ 289,05$ milhões em 2006 para $\mathrm{R} \$ 531,36$ milhões em 2015, sofrendo uma variação de 183\% entre os dois anos. Salvador (2015) apresenta que, de 2010 para 2014, 0 esporte foi um dos setores que teve maior aumento de gastos tributários.

O aumento de gasto tributário ao longo dos governos Lula e Dilma se deveu, em grande parte, à novas isenções/desonerações tributárias que foram criadas ao longo do tempo, com destaque para a LIE em 2007 e para as referentes aos megaeventos esportivos, a partir de 2012. No setor esportivo, os gastos tributários acabaram sendo uma alternativa importante de financiamento, tanto que, a partir de 2012, este financiamento passou a ser uma fonte de recurso mais volumosa que a fonte orçamentária (CARNEIRO, 2018). No âmbito mais geral dos governos Lula e Dilma, a ampliação de gastos tributários foi uma das estratégias anticíclicas para lidar com a crise estrutural do capital (SALVADOR, 2015; PINTOS et al., 2016), destarte, os gastos tributários com esporte se alinharam às estratégias econômicas dos governos Lula e Dilma, tanto que seu crescimento acompanhou o crescimento dos gastos tributários totais (Tabela 2).

O único gasto tributário para o esporte que teve recursos em todos os anos foi a desoneração das entidades recreativas sem fins lucrativos ${ }^{4}$. Somente essa representou

4 Buscou-se junto à RFB dados detalhados sobre quais são e quanto recebeu cada entidade recreativa sem fins lucrativos no período, contudo, apontaram não poder divulgar estes dados por serem sigilosos. 
$51,45 \%$ ( $R \$ 2,64$ bilhões) de todos os gastos tributários com esporte. Estas entidades tiveram grande crescimento a partir dos anos 1990, sendo que, além de receberem o montante da desoneração supracitada ao longo do período, houve também o recebimento de recursos de loterias federais, patrocínios das estatais e recebimento de recursos para implementar políticas esportivas do Ministério do Esporte (ALMEIDA; MARCHI JÚNIOR, 2011 e 2012; PEREIRA, 2017; CARNEIRO, 2018). As entidades recreativas sem fins lucrativos são extremamente heterogêneas (CORREIA, 2012).

O segundo maior gasto tributário com o esporte envolveu a isenção de IRPF e IRPJ para patrocínios e doações pela LIE, que representou $33,97 \%$ ( $R \$ 1,74$ bilhões) de todo 0 gasto tributário no período. Na Figura 1 é possível notar que 0 incremento dessa isenção elevou o quantitativo de gastos tributários para o esporte a partir de 2007 . Enquanto 98,00\% destes recursos foram provenientes de isenção de IRPJ, apenas 2,00\% foram derivados de isenção de IRPF. O maior interesse de Pessoas Jurídicas em patrocinar/doar recursos para projetos esportivos ocorre devido ao retorno de imagem que recebem ao associar sua marca ao esporte, sendo esta marca vinculada ao ganho de mercado, sendo que fazem isso sem custo nenhum, pois os recursos isentados seriam pagos ao Estado como Imposto de Renda (MATIAS et al. 2015; CARNEIRO, 2018). A concentração de recursos da LIE no esporte de alto rendimento, em determinadas modalidades e regiões do país fez com que Matias et al. (2015) concluíssem, em seu estudo, que a LIE não contribui para a democratização do acesso ao esporte no Brasil.

A partir de 2012 foram iniciadas as desonerações para realização dos megaeventos esportivos, especificamente, a Copa das Confederações FIFA 2013, a Copa FIFA 2014 e os Jogos Rio 2016. O gasto tributário para todos estes megaeventos representou $14,54 \%$ (R\$ 748,30 milhões) de todos os gastos tributários com esporte. De 2012 a 2014 houve recursos para o Regime Especial de Tributação para Construção, Ampliação, Reforma ou Modernização de Estádios de Futebol (RECOPA), destinado para a infraestrutura dos estádios para a Copa das Confederações FIFA 2013 e a Copa FIFA 2014, tendo totalizado R \$ 273,98 milhões. De 2012 a 2015 houve gasto tributário para realização/organização da Copa das Confederações FIFA 2013 e a Copa FIFA 2014, tendo somado R\$ 148,47 milhões. Já de 2013 a 2015, os Jogos Rio 2016 tiveram $R \$ 325,85$ milhões de gastos tributários.

A criação das referidas desonerações para a realização dos megaeventos esportivos no Brasil esteve diretamente relacionada às definições do Plano Decenal de Esporte plano criado a partir da III Conferência Nacional do Esporte de 2010. Com o fim do ciclo dos megaeventos esportivos no Brasil, com a realização dos Jogos Rio 2016, houve a redução dos gastos tributários com esporte, uma vez que eram desonerações com prazo para acabar (Quadro) 1 - o portal Transparência no Esporte (2019) mostra que houve redução dos gastos tributários com esporte em 2017 e 2018, não havendo gasto tributário com megaeventos em 2018. Para Vainer (2011), as isenções tributárias para os megaeventos esportivos contribuíram para que se criasse no Brasil um Estado de exceção, isto é, criando regras e condições jamais vistas para que fossem realizados.

As duas isenções/desonerações que contaram com valores mais diminutos foram: a isenção para eventos esportivos ( $\mathrm{R} \$ 278,36$ mil) e a isenção de equipamentos e materiais esportivos (totalizou R $\$ 35,22$ mil) - esta última RFB (BRASIL, 2018b) não conseguiu acessar em todos os anos. 


\section{DIRECIONAMENTO DO GASTO TRIBUTÁRIO}

Analisadas as fontes de financiamento e a magnitude dos gastos tributários se passa a discutir o direcionamento destes recursos. Estudos como os de Mascarenhas (2016), Carneiro (2018) e Carneiro e Mascarenhas (2018) propõem a distinção de cinco categorias de gasto: Esporte de Alto Rendimento (EAR); Esporte, Educação, Lazer e Inclusão Social (EELIS); Megaeventos; Infraestrutura; e Gestão. A partir dos dados de gastos tributários são distinguidas as categorias: EAR, EELIS e Megaeventos, conforme pode ser notado na Figura 2 - as categorias Infraestrutura e Gestão não tiveram recursos de gastos tributários no período.

Figura 2- Direcionamento do gasto tributário com esporte - Série 2006 a 2015 (valores em \%)

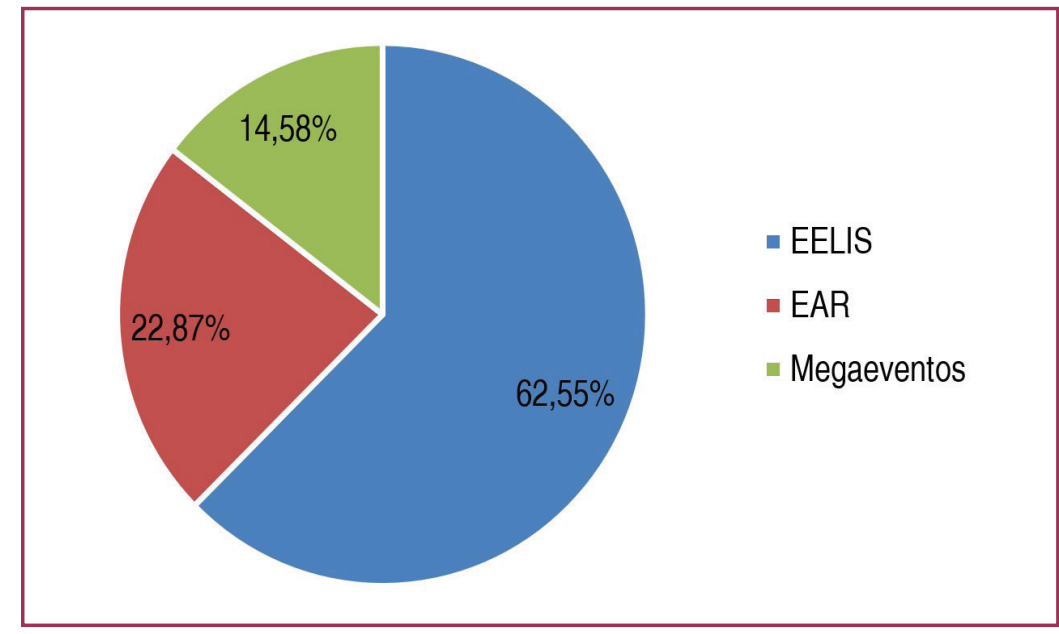

Fonte: Demonstrativos de gastos tributários (BRASIL, 2018b). (Elaboração própria)

A categoria de gasto que teve mais recursos no período foi EELIS, tendo representado $62,55 \%$ de todo gasto tributário com esporte. Dos R $\$ 3,21$ bilhões para esta categoria, $82,24 \%$ foram de desoneração das entidades recreativas sem fins lucrativos e $17,76 \%$ foram dos projetos de esporte educacional e de participação da LIE. Salvador (2015) aponta que, em momentos de crise econômica, o Estado acaba fortalecendo a oferta de serviços sociais por entidades sem fins lucrativos, elemento que se faz bastante presente no esporte (CORREIA, 2012).

A segunda categoria de gasto que teve mais recurso foi o $E A R$, com $R \$ 1,17$ bilhão. Deste total, $99,97 \%$ foram fruto de projetos de EAR, que receberam recursos da LIE, 0,02\% de isenção de eventos esportivos e $0,003 \%$ foi de isenção de equipamentos e materiais esportivos. A LIE foi direcionada ao longo do tempo, sobretudo, para o EAR, sendo isso uma infringência legal daquilo que foi definido por sua legislação (MATIAS et al., 2015; CARNEIRO, 2018), isto é, não se poderia concentrar em uma das dimensões do esporte (BRASIL, 2006). O foco da LIE em projetos de EAR em detrimento de projetos de EELIS se relaciona com a maior visibilidade proporcionada por aqueles.

A categoria de gasto que menos recebeu recursos foi a de Megaeventos, foram $\mathrm{R} \$$ 748,30 milhões, gasto este realizado apenas de 2012 a 2015 - neste período, 29,04\% dos gastos tributários foram com a referida categoria. Athayde (2011) aponta que a partir da realização dos Jogos Pan Rio 2007 houve uma inflexão da política esportiva para a realização dos megaeventos esportivos, estes se tornaram o princípio para organizar a agenda política 
de esporte no Brasil (MASCARENHAS et al., 2012). Os recursos destinados aos megaeventos esportivos, além de estarem associados a elevar o Brasil à condição de potência esportiva, "[...] têm alavancado a cadeia produtiva do esporte e mobilizado significativos investimentos governamentais, com impacto em diversos setores da economia." (MASCARENHAS, 2016, p. 963). Destarte, enquanto os gastos tributários com os megaeventos cumpriram um papel econômico, aqueles com EELIS e EAR tiveram um papel social importante na política esportiva.

Embora na fonte de gastos tributários tenha ocorrido privilégio da categoria EELIS, no âmbito mais geral do financiamento federal do esporte houve uma atuação contundente dos governos Lula e Dilma para garantirem mais recursos para o setor, principalmente, para o EAR e os megaeventos esportivos - exemplo disso é a desoneração para estes. Com a vinda dos megaeventos para o Brasil, foram construídos mecanismos para garantir que mais recursos fossem direcionados ao EAR para que os atletas brasileiros tivessem uma boa participação neles (CARNEIRO, 2018).

\section{CONSIDERAÇÕES FINAIS}

Os gastos tributários passaram a ser uma importante fonte de financiamento público do esporte brasileiro, tendo sido em alguns anos do governo Dilma maiores que o gasto orçamentário com o setor. Para que isso acontecesse, houve ao longo dos governos Lula e Dilma a criação de legislações que garantiram o aumento dos gastos tributários. Os gastos tributários com esporte não tiveram grande representatividade em relação aos gastos tributários totais, contudo, contribuíram de maneira significativa para o incremento do financiamento esportivo brasileiro.

Em relação ao direcionamento dos gastos tributários, teria sido priorizada a categoria EELIS, fruto em grande parte dos recursos desonerados para as entidades recreativas sem fins lucrativos. Já na categoria EAR, a centralidade esteve sobre a LIE, especialmente, a partir de IRPJ. O gasto com megaeventos ocorreu no governo Dilma, tendo sido a maior parte para os Jogos Rio 2016.

O processo de aumentar os gastos tributários com esporte é apenas a expressão do que ocorreu em âmbito mais geral dos governos Lula e Dilma, uma vez que as desonerações tributárias foram formas do Estado auxiliar aqueles com maior renda em momento de crise do capitalismo. A realização dos megaeventos esportivos foi uma das formas de alavancar a economia brasileira, sobretudo no governo Dilma, e para se concretizarem foram realizadas desonerações tributárias (SALVADOR, 2015; PINTO et al. 2016). Assim, por um lado os gastos tributários com esporte se associaram com questões econômicas dos governos supracitados, mas também ocorreu o aspecto social de desenvolver/fortalecer o setor esportivo.

Esta pesquisa se coloca como uma ferramenta importante para dar visibilidade a uma parte do financiamento esportivo que tem sido pouco estudada. A pesquisa teve a limitação de utilizar apenas os gastos tributários efetivos a partir da RFB, tendo possibilitado que as análises fossem realizadas apenas de 2006 a 2015, além disso, se limitou a trabalhar com gastos tributários da função "Desporte e lazer", não analisando os gastos de outras funções com esporte.

É importante que novos estudos possam se dedicar a esta parte dos recursos para o esporte, aprofundando as análises sobre as desonerações das entidades recreativas sem fins 
lucrativos, a LIE e as desonerações para os megaeventos. Além disso, é importante que novos estudos, que buscam ter um olhar de totalidade do financiamento esportivo brasileiro, possam ter por base os gastos tributários com o setor, possibilitando novas abordagens analíticas.

\section{REFERÊNCIAS}

ALMEIDA, Bárbara; MARCHI JÚNIOR, Wanderley. Comitê Olímpico Brasileiro e o financiamento das confederações brasileiras. Revista Brasileira de Ciências do Esporte, v. 33, n. 1, p. 163179, jan./mar. 2011.

ALMEIDA, Bárbara; MARCHI JÚNIOR, Wanderley. A relação Governo Federal e Comitê Olímpico Brasileiro com base na análise da Lei 10.264/2001 (Agnelo-Piva) no período de 2005 a 2008. Pensar a Prática, v. 15, n. 3, p. 575595, jul./set. 2012.

ATHAYDE, Pedro Fernando Avalone. O "lugar do social" na Política de Esporte do Governo Lula. SER Social, v. 13, n. 28, p. 184-209, jan./jun. 2011.

ATHAYDE, Pedro; SALVADOR, Evilasio; MASCARENHAS, Fernando. Primeiras aproximações de uma análise do financiamento da política nacional de esporte e lazer no governo Lula.

Revista Brasileira de Ciências do Esporte, v. 37, n. 1, p. 2-10, jan./mar. 2015.

BASTIDAS, Marina Gallego; BASTOS, Flávia da Cunha. A Lei de Incentivo Fiscal para o desporto e a formação de atletas no Brasil. Revista Intercontinental de Gestão Desportiva, v. 1, n. 2, p. 111-121, jul./dez. 2011.

BEGHIN, Nathalie; CHAVES, José; RIBEIRO, José. Gastos Tributários Sociais de Âmbito Federal: Uma Proposta de Dimensionamento. In: CASTRO, Jorge; SANTOS, Cláudio; RIBEIRO, José (Orgs.). Tributação e equidade no Brasil. Brasília: IPEA, 2010. p. 375-408.

BOUDENS, Emile Paulo Johannes. 0 financiamento do esporte no primeiro mandato de Lula (2003-2006). Rio de Janeiro: Usina das Letras, 2007.

BRASIL. Lei no 11.438, de 29 de dezembro de 2006. 2006. Disponível em: http://www.planalto. gov.br/ccivil 03/ Ato2004-2006/2006/Lei/L11438.htm. Acesso em: 10 out. 2018.

BRASIL. Ministério da Fazenda. Receita Federal. Demonstrativo dos Gastos Tributários Bases Efetivas - 2015 - Série 2013 a 2018. Brasília: mar. 2018a. Disponível em: http://receita. economia.gov.br/dados/receitadata/renuncia-fiscal/demonstrativos-dos-gastos-tributarios/arquivos-eimagens/ano-calendario-2015-serie-2013-a-2018.pdf. Acesso em: 07 out. 2018.

BRASIL. Ministério da Fazenda. Receita Federal. Renúncia fiscal. 2018b. Disponível em: https://receita.economia.gov.br/dados/receitadata/renuncia-fiscal/demonstrativos-dos-gastostributarios/bases-efetivas. Acesso em: 05 out. 2018.

BRASIL. Portal da Legislação do Governo Federal. Brasília. Disponível em: http://www4. planalto.gov.br/legislacao/. Acesso em: 10 out. 2018.

BRASIL. Tribunal de Contas da União. Auditoria destinada a verificar a aplicação da Lei de Incentivo ao Esporte. TC 022.993/2009-9. 2009. Disponível em: http://www.tcu.gov.br/consultas/ juris/docs/judoc/acord/20130205/ac 00920313 p.doc. Acesso em: 26 jan. 2019. 
CARNEIRO, Fernando Henrique Silva. O financiamento do esporte no Brasil: aspectos da atuação estatal nos governos Lula e Dilma. 2018. 385 f. Tese (Doutorado em Educação Física) -Universidade de Brasília, Brasília, 2018.

CARNEIRO, Fernando Henrique Silva; MASCARENHAS, Fernando. O financiamento esportivo brasileiro: proposta de metodologia crítica de análise. E-Legis, v. 11, n. Especial - Pesquisas e Políticas sobre Esporte II, p. 119-140, nov. 2018.

CARNEIRO, Fernando Henrique Silva et al. Orçamento do esporte no governo Dilma: a primazia dos interesses econômicos e o direito escanteado. Revista Brasileira de Ciências do Esporte, 2019. Disponível em: http://www.rbceonline.org.br/pt-pdf-S0101328917301026. Acesso em: 10 mar. 2019.

CASTRO, Suélen Barboza Eiras de. Políticas públicas para o esporte e lazer e o ciclo orçamentário brasileiro (2004-2011): prioridades e distribuição de recursos durante os processos de elaboração e execução orçamentária. 2016. 235 f. Tese (Doutorado em Educação Física) - Universidade Federal do Paraná, Curitiba, 2016.

CORREIA, Juliane Cristine Alves. 0 setor privado sem fins lucrativos e as políticas públicas de esporte e lazer (2008-2011). 2012. 131 f. Dissertação. (Mestrado em Educação Física) Universidade Estadual de Campinas, Campinas, 2012.

MASCARENHAS, Fernando. O orçamento do esporte: aspectos da atuação estatal de FHC a Dilma. Revista Brasileira de Educação Física e Esporte, v. 30, n. 4, p. 963-980, out./dez. 2016.

MASCARENHAS, Fernando et al. O Bloco Olímpico: Estado, organização esportiva e mercado na configuração da agenda Rio 2016. Revista da ALESDE, v. 2, n. 2, p. 15-32, out. 2012.

MATIAS, Wagner Barbosa et al. A Lei de Incentivo Fiscal e o (não) direito ao esporte no Brasil. Movimento, v. 21, n. 1, p. 95-110, jan./mar. 2015.

PELLEGRINI, Josué Alfredo. Gastos Tributários: conceitos, experiência internacional e o caso do Brasil. Brasília: Textos para Discussão n. 159, Núcleo de Estudos e Pesquisas da Consultoria Legislativa, 2014. Disponível em: https://www12.senado.leg.br/publicacoes/estudoslegislativos/tipos-de-estudos/textos-para-discussao/td159/. Acesso em: 11 mar. 2019.

PEREIRA, Claudia Catarino. As empresas estatais e o financiamento do esporte nos governos Lula e Dilma. 2017. 187 f. Dissertação (Mestrado em Educação Física) - Faculdade de Educação Física, Universidade de Brasília, Brasília, 2017.

PINTO, Eduardo Costa et al. A economia política dos governos Dilma: acumulação, bloco no poder e crise. UFRJ, Instituto de Economia. Texto para Discussão 004, 2016. Disponível em: http://www.ie.ufri.br/images/pesquisa/publicacoes/discussao/2016/TD IE 0042016 COSTA PINTO et al.pdf. Acesso em: 01 mar. 2019.

SALVADOR, Evilasio. Financiamento tributário da política social no pós-Real. In: SALVADOR, Evilasio et al. (orgs.). Financeirização, fundo público e política social. São Paulo: Cortez, 2012. p. 123-152.

SALVADOR, Evilasio. Renúncias tributárias: os impactos no financiamento das políticas sociais no Brasil. Brasília: INESC; OXFAM Brasil, 2015.

SALVI, André; PAULA, Etélia; LOURES, Marcelo. Gastos Governamentais Indiretos, de Natureza Tributária - Conceituação. Brasília: Secretaria da Receita Federal, 2003. (Estudos tributários 12). 
TEIXEIRA, Marcelo Resende et al. Esporte, fundo público e pequena política: os reveses de um orçamento (r)emendado. Movimento, v. 24, n. 2, p. 593-606, abr./jun. 2018.

TEIXEIRA, Marcelo; MATIAS, Wagner; MASCARENHAS, Fernando. O esporte olímpico no Brasil: recursos financeiros disponibilizados para Olimpíadas Londres 2012. Revista Brasileira de Ciências do Esporte, v. 39, n. 3, p. 284-290, jul./set. 2017.

TRANSPARÊNCIA NO ESPORTE. Brasília: Universidade de Brasília, 2019. Disponível em: http://www.transparencianoesporte.unb.br. Acesso em: 13 mar. 2019.

VAINER, Carlos. Cidade de Exceção: Reflexões a Partir do Rio de Janeiro. ENCONTRO NACIONAL DA ANPUR, 14. Anais... Rio de Janeiro, 2011. Disponível em: https://br.boell.org/ sites/default/files/downloads/carlos vainer ippur cidade de excecao reflexoes a partir do rio de janeiro.pdf. Acesso em: 10 mar. 2019.

VILLELA, Luiz; LEMGRUBER, Andrea; JORRATT, Michael Luiz Villela. Los Presupuestos de Gastos Tributarios: Conceptos y Desafíos de Implementación. Washington: Associación Internacional de Presupuesto público, 2009. (IDB working paper series, no 131).

\section{Apoio:}

Conselho Nacional de Desenvolvimento Científico e Tecnológico (CNPq) pelo Edital Universal 14/2014 e o primeiro autor foi beneficiário do Programa Institucional de Bolsas de Qualificação de Servidores do Instituto Federal de Goiás (IFG). 